\title{
In vitro studies of the toxic effects of silver nanoparticles on HeLa and U937 cells
}

\author{
This article was published in the following Dove Press journal: \\ Nanotechnology, Science and Applications \\ 5 March 2015 \\ Number of times this article has been viewed
}

\author{
Said I Kaba \\ Elena M Egorova \\ Institute of General Pathology and \\ Pathophysiology, Moscow, Russia
}

Correspondence: Said I Kaba Institute of General Pathology and Pathophysiology, 8 Baltijskaya Street, Moscow 125315, Russia Tel +7 9262423045

Email said.kaba@gmail.com

\begin{abstract}
In the last decade, much attention has been paid to studies of the effect of silver nanoparticles (Ag NPs) on tumor cells. Apart from elucidation of the mechanism of NPs' interaction with mammalian cells, these studies are aimed at discovering new effective antitumor drugs. In this work, we report about the toxic effects of Ag NPs observed on two types of tumor cells: HeLa (adhesive cells) and U937 (suspension cells). The Ag NPs were obtained by an original method of biochemical synthesis. Particle size was $13.2 \pm 4.72 \mathrm{~nm}$, and zeta potential was $-61.9 \pm 3.2 \mathrm{mV}$. The toxicity of Ag NPs in the concentration range $0.5-8.0 \mu \mathrm{g} \mathrm{Ag} / \mathrm{mL}$ was determined by means of 3-(4,5-dimethylthiazol-2-yl)-2,5-diphenyltetrazolium bromide assay and cytofluorometry after 4 and 24 hours' incubation. It was found that Ag NPs had high toxicity toward both cell types. The minimal concentrations where a toxicity effect was registered (toxicity thresholds) lied in the range $0.5-2.0 \mu \mathrm{g} \mathrm{Ag} / \mathrm{mL}$. In parallel with the Ag NP solution, cells were incubated with water solutions of the NP stabilizer (aerosol-OT) and $\mathrm{Ag}^{+}$ions (as silver nitrate). It was shown that aerosol-OT had no effect on the viability on HeLa cells, but was moderately toxic toward U937, though less dangerous for these cells than Ag NPs. With $\mathrm{Ag}^{+}$ions, for HeLa no toxic effect was observed, while for U937 they were as toxic as the $\mathrm{Ag}$ NPs. The data obtained indicate that Ag NPs as used in this study may prove to be useful for the creation of medicines for cancer therapy.
\end{abstract}

Keywords: silver nanoparticles, cell viability, apoptosis, tumor cells

\section{Introduction}

In the last decade, much attention has been paid to studies of biological (toxic) effects of silver nanoparticles (Ag NPs). The main reason is that these NPs demonstrate strong bactericidal activity, both in the form of solutions and as components of nanocomposite materials. ${ }^{1-5}$ A wide spectrum of pathogen microbes affected, in combination with the relatively simple and cheap technology of production, are responsible for the fact that Ag NPs have found a lot of applications in the production of consumer products and materials for medical purposes. ${ }^{6-8}$ Such an intensive usage of NPs raised the question

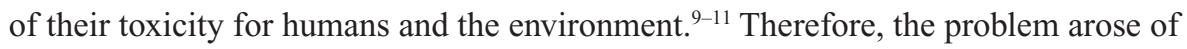
determination of conditions for safe application of Ag NPs, so as to make their valuable advantages much more significant than their negative effects. Works in this direction belong to the field of nanotoxicology, the newly formed branch of toxicological studies, dealing with the toxic effects of NPs conditioned by their specific physicochemical, optical, and mechanical properties. ${ }^{10,12-14}$

The main objects used in in vitro studies of Ag NP action are microbial species and cultured normal or tumor mammalian cells; the results obtained are summarized 
in recent books and reviews. ${ }^{2,15-19}$ With normal cells, two main aims are pursued by researchers. First, to evaluate the extent of the NPs' cytotoxicity, in particular to elucidate whether the NPs' bactericidal concentration found in experiments on bacteria is toxic for animal or human cells, and hence whether the given application of NPs is dangerous for humans. Second, it is important to define the mechanism of NPs' action, including the influence of their main parameters (size, form, surface charge, and stabilizing shell) on cell viability and functions, as well as to provide visualization of the ways of penetration of NPs into the cell interior. Attention has also been paid to the role of silver ions in the toxicity of NPs. ${ }^{20,21}$ With tumor cells, apart from elucidation of the mechanism of cytotoxicity, the purpose is to obtain data allowing the application of Ag NPs in cancer therapy. ${ }^{22,23}$

Analysis of the data available reveals problems arising mainly from the underestimation of the significance of the way applied for NPs preparation, which determines their properties and behavior in experimental conditions. The importance of the method used for the synthesis of metal NPs was emphasized in our papers dealing with the studies on biological effects of Ag NPs, ${ }^{1,24}$ and more recently in a monograph devoted to the same effects of metal NPs. ${ }^{2}$ For example, there are few reports of studies of both antimicrobial activity and cytotoxicity on the same NP preparation. ${ }^{22,25}$ In the other publications available, comparison of the working bactericidal concentrations of Ag NPs with those provoking cell-toxic effects was made with different NP preparations. ${ }^{21,26,27}$ As shown in our book, ${ }^{2}$ such a comparison cannot be made correctly, since differently prepared NPs have different parameters affecting their biological activity.

In our researches, we used Ag NPs obtained by an original method of biochemical synthesis in studies of their action on various biological objects, including bacteria, viruses, ${ }^{1,28,29}$ uncellular slim mold, ${ }^{30,31}$ unicellular alga, and plant seeds. ${ }^{32}$ In the course of these studies, we worked out the requirements for NP preparation and experimental procedure necessary for revealing the pure effects of NPs on the object under consideration.

In this paper, we report our first results obtained in studies of Ag NPs' effect on the viability of human tumor cells. Our aim was to determine the influence of NP concentration and time of incubation on the percentage of living cells, and to reveal the corresponding changes in their state (apoptosis and necrosis).

\section{Materials and methods \\ Reagents}

Dulbecco's modified Eagle's medium (DMEM), Roswell Park Memorial Institute (RPMI) 1640 cell media, and bovine serum albumin (BSA) were purchased from Thermo Fisher Scientific (Waltham, MA, USA). Phosphate-buffered saline (PBS) and dimethyl sulfoxide (DMSO) were purchased from Sigma-Aldrich (St Louis, MO, USA). MTT (3-[4,5dimethylthiazol-2-yl]-2,5-diphenyltetrazolium bromide) was purchased from Amresco (Solon, OH, USA). An Annexin V-FITC Apoptosis Detection Kit I was purchased from BD Biosciences (Franklin Lakes, NJ, USA).

For the NP preparation, silver nitrate was used (chemical purity), and 27\% ammonium hydroxide obtained from Labtech (Moscow, Russia), quercetin(Qr, 3,5,7,3',4'-pentahydroxyflavon) obtained from Merck, and aerosol-OT (AOT; bis-[2-ethylhexyl] sulfosuccinate [sodium salt]) obtained from Sigma-Aldrich.

\section{Cell lines}

A HeLa adherent cell line was obtained from the American Type Culture Collection (ATCC; Manassas, VA, USA). Cells were maintained in DMEM supplemented with $10 \%$ $(\mathrm{v} / \mathrm{v})$ BSA in a $95 \%(\mathrm{v} / \mathrm{v})$ humidified atmosphere and $5 \%$ $(\mathrm{v} / \mathrm{v}) \mathrm{CO}_{2}$ at $37^{\circ} \mathrm{C}$. Cells were seeded near confluence a day before incubation with NPs.

A U937 suspended cell line (ATCC CRL 1593, DSM ACC 5, and ECACC 85011440 collections) was obtained from the Russian Cell Culture Collection (Institute of Cytology of Russian Academy of Sciences, St Petersburg, Russia). Cells were maintained in RPMI 1640 medium supplemented with $10 \%(\mathrm{v} / \mathrm{v}) \mathrm{BSA}$ in a $95 \%(\mathrm{v} / \mathrm{v})$ humidified atmosphere and $5 \%(\mathrm{v} / \mathrm{v}) \mathrm{CO}_{2}$ at $37^{\circ} \mathrm{C}$. Optimal cell-seeding density was $2 \times 10^{5}-9 \times 10^{5}$ cells $/ \mathrm{mL}$. Cells were seeded a day before incubation with NPs.

\section{Silver nanoparticle synthesis and characterization}

Ag NPs were obtained first in micellar solution (in organic solvent) by means of an original method (biochemical synthesis) based on the reduction of silver ions in reverse micelles by the natural flavonoid quercetin (Qr). The reverse micelles are formed from AOT, a synthetic anionic surface-active substance widely used for the creation of reverse micellar solutions, including those used for the synthesis of metal NPs. ${ }^{33,34}$ The proper choice of system composition (concentrations of reagents, hydration extent, metal salt, solvent) allows the provision of a sufficiently high rate of synthesis, stability, 
and yield of NPs. Principles of the method and details of Ag NP preparation are given elsewhere. 1,24,35 $^{2}$

Briefly, the Qr micellar solution in AOT/isooctane is first prepared according to a previously described procedure..$^{35,36}$ The Qr concentration $\left(\mathrm{C}_{\mathrm{Qr}}\right)$ in micellar solution is determined from spectrophotometric measurements by using the extinction coefficient $\left(\varepsilon=1.8 \times 10^{4} \mathrm{~L} / \mathrm{mol} \cdot \mathrm{cm}\right)$, as previously described. ${ }^{36}$ Then, metal salt is added as water solution to the concentration and hydration extent desired; in this work, water $\mathrm{Ag}\left(\mathrm{NH}_{3}\right)_{2} \mathrm{NO}_{3}$ solution (prepared by the addition of ammonium hydroxide to silver nitrate solution) was introduced into the Qr micellar solution to a silver salt concentration $\left(\mathrm{C}_{\mathrm{Ag}}\right)$ of $1 \mathrm{mM}$ and hydration extent of $\mathrm{w}=[\mathrm{H} 2 \mathrm{O}] /[\mathrm{AOT}]=3.7$. After being shaken for several minutes, almost colorless Qr solution acquired the intense red-brown coloration that indicated the appearance of NPs. Measurements of optical absorption spectra showed that the NP formation took no more than 2 days, as seen from the absence of further changes of the characteristic absorption band (435 nm). The Ag NP concentration $\left(\mathrm{C}^{0}{ }_{\mathrm{NP}}\right)$ in micellar solution was obtained from the measured optical density in the absorption-band maximum at this stationary stage and the extinction coefficient $\left(\varepsilon=1.03 \times 10^{4} \mathrm{~L} / \mathrm{mol} \cdot \mathrm{cm}\right)$ as previously described. ${ }^{36}$ The yield of NPs $\left(\beta_{\mathrm{NP}}=\left[\mathrm{C}^{0}{ }_{\mathrm{NP}} / \mathrm{C}_{\mathrm{Ag}}\right] \times 100 \%\right)$ as a function of $\mathrm{C}_{\mathrm{Qr}} / \mathrm{C}_{\mathrm{Ag}}$ allows the determination of the region of this relation where the yield is constant and equal to $100 \%$, corresponding to the complete reduction of metal ions. ${ }^{2,36}$ For the parameters used in this work, the Ag NP concentration was determined 3 days after the beginning of synthesis: $\mathrm{C}_{\mathrm{NP}}^{0} \approx 1 \mathrm{mM}$, ie, $\beta_{\mathrm{NP}} \approx 100 \%$.

The water solution of the Ag NPs is obtained by their transfer from the micellar solution into the water phase by means of a specially developed procedure. ${ }^{1,37}$ In water solution, the NPs are stabilized by the AOT bilayer shell bearing negative surface charge.

The Ag NP concentration in water solution is determined from the optical density of the corresponding absorption band using the extinction coefficient $\left(\varepsilon=1.14 \times 10^{4} \mathrm{~L} /\right.$ $\mathrm{mol} \cdot \mathrm{cm}$ ) obtained in independent measurements; details may be found in our previous paper and in a recent book..$^{2,37}$ The concentration of stabilizer (AOT) is found by means of the standard procedure used for the determination of anionic surface-active substances in water. ${ }^{38}$ In the water solution used in this work (referred to as "initial solution"), the $\mathrm{Ag}$ $\mathrm{NP}$ concentration (equivalent to metallic silver) was $1 \mathrm{mM}$ $(108 \mu \mathrm{g} / \mathrm{mL})$ and AOT concentration was $2 \mathrm{mM}$.

Size distribution and zeta potential of the NPs in water solution were found by photon correlation spectroscopy
(PCS) on ZetaPALS (Brookhaven Instruments, Holtsville, NY, USA). Morphology, structure, and size distribution were determined by transmission electron microscopy (TEM) on a Leo 912 AB Omega microscope (Carl Zeiss, Oberkochen, Germany). Samples for microscopy were prepared by placing $3 \mu \mathrm{L}$ of the Ag NP water solution on the formvar-coated copper grid, with subsequent drying for 30 minutes on air. From the data given by electron microscopy, a histogram was created for 519 particles.

\section{Cell incubation with silver nanoparticles}

Cells were grown in appropriate plates (96- or 12-well) depending on assay type and under the conditions described in the "Cell lines" section. Then, aliquots of initial Ag NP solution were added to cell medium to final NP concentrations of $0.5,1.0,2.0,4.0$, and $8.0 \mu \mathrm{g} / \mathrm{mL}$. After that, the cell medium was gently mixed by pipetting in each well. Cells were incubated for 4 and 24 hours in $95 \%$ (v/v) humidified atmosphere and $5 \%(\mathrm{v} / \mathrm{v}) \mathrm{CO}_{2}$ at $37^{\circ} \mathrm{C}$. The effect of NPs was also compared with that of silver ions or stabilizer (AOT); for this purpose, cells were incubated with either silver nitrate or AOT water solution added to the final concentrations of metallic silver or AOT introduced at the corresponding dilutions of the initial Ag NP solution (see also the "Estimation of cell viability by MTT assay" section). Incubation with deionized water was used as a negative control.

\section{MTT viability assay}

Cells were grown in 96-well plates in $200 \mu \mathrm{L}$ of medium volume per well and incubated with NPs, AOT, or $\mathrm{Ag}^{+}$ ions, as mentioned in the previous section. After treatment, the medium was removed and cells were washed twice with PBS (pH 7.4) at $37^{\circ} \mathrm{C}$ and placed into PBS. Then, the MTT solution was added to the cells to a concentration of $1 \mathrm{mg} / \mathrm{mL}$, and cells were incubated for 3 hours in standard conditions. After incubation, PBS was removed and DMSO was added to dissolve formed formazan crystals. The optical density of formazan solution in DMSO was measured by a Chameleon V microplate reader (Hidex, Turku, Finland) at $540 \mathrm{~nm}$. Cell viability for each concentration point was calculated as the ratio of the mean optical density of replicated wells relative to that of the negative control.

\section{Measurement of apoptotic levels by flow cytofluorometry}

To detect apoptotic events, annexin V conjugated with fluorescein isothiocyanate (FITC) and propidium iodide (PI) 
were used. The procedure was performed using the Annexin V-FITC Apoptosis Detection Kit I and according to the manufacturer's instructions. Cells were grown in 12-well plates in $1 \mathrm{~mL}$ of medium volume per well and then incubated with NPs, AOT, or $\mathrm{Ag}^{+}$ions. After being treated with NPs, cells were washed in cold PBS, then resuspended in annexin $V$ binding buffer; after that, annexin V and PI were added. After being incubated for 15 minutes, stained cells were diluted with binding buffer, placed into an ice bath, and then analyzed using a FACSCalibur flow cytometer (BD Biosciences). Fluorescence levels of FITC and PI were measured.

\section{Statistical analysis}

All experiments were performed in triplicate, and all data are presented as means \pm standard deviation. Statistical significance was determined by Student's $t$-test.

\section{Results}

\section{Silver nanoparticles}

Typical electron micrograph and diffraction pattern of Ag NPs in the initial water solution are shown in Figure 1. The NPs were approximately spherical (Figure 1A); electron diffraction revealed a face-centered cubic crystal structure with parameters corresponding to those of Ag crystal (Figure 1B). Particle-size distribution is given in Figure 2A. Gauss approximation (for $90 \%$ of the particles) gave a diameter of $13.4 \pm 4.7 \mathrm{~nm}$. Mean size measurement by PCS resulted in 32.0 $\pm 0.6 \mathrm{~nm}$ (Figure $2 \mathrm{~B}$ ), ie, the mean diameter was larger than that found from TEM. The enhancement of particle sizes measured by PCS for metal (at least silver and gold) NPs compared to those given by TEM has been reported in the literature ${ }^{39}$ as well as in our previous publications. ${ }^{1,40}$ The zeta potential of Ag NPs was found to be $-61.9 \pm 3.2 \mathrm{mV}$; therefore, the particles were negatively charged as could be expected for their stabilizing shell from AOT molecules with anionic ionizable groups.

\section{Estimation of cell viability by MTT assay}

The cytotoxicity of the NPs was characterized by determination of 1) cell viability and 2) cell death levels (early apoptosis, late apoptosis, and necrosis). Cell viability was measured by the well-known MTT assay, based on evaluation of the activity of mitochondrial dehydrogenases. When incubated with cells studied, MTT as substrate is reduced by these enzymes to formazan dye, and then its concentration in DMSO solution is found from the optical density of the relevant absorption band. ${ }^{41,42}$ MTT assays were performed after 4 and 24 hours' incubation with various NP concentrations (see the "Cell incubation with silver nanoparticles" section) introduced as the corresponding dilutions of the initial solution of Ag NPs.

To check the influence of the stabilizer (AOT) and to throw light also on the role of silver ions in the toxic effect of Ag NPs, in parallel with the NP solution the cells were incubated with water solutions of either AOT or silver nitrate. Here, the AOT concentrations were equal to those introduced with the NP solution (as the corresponding dilutions of $2 \mathrm{mM}$ AOT solution [see the "Silver nanoparticle synthesis and characterization" section]), and silver ion concentrations were equal to metallic silver concentrations introduced with Ag NPs (as if all the NPs would dissociate into ions). The percentages of active cells (marked as cell viability) as a function of silver (Ag NPs or $\mathrm{Ag}^{+}$ions) concentration, together
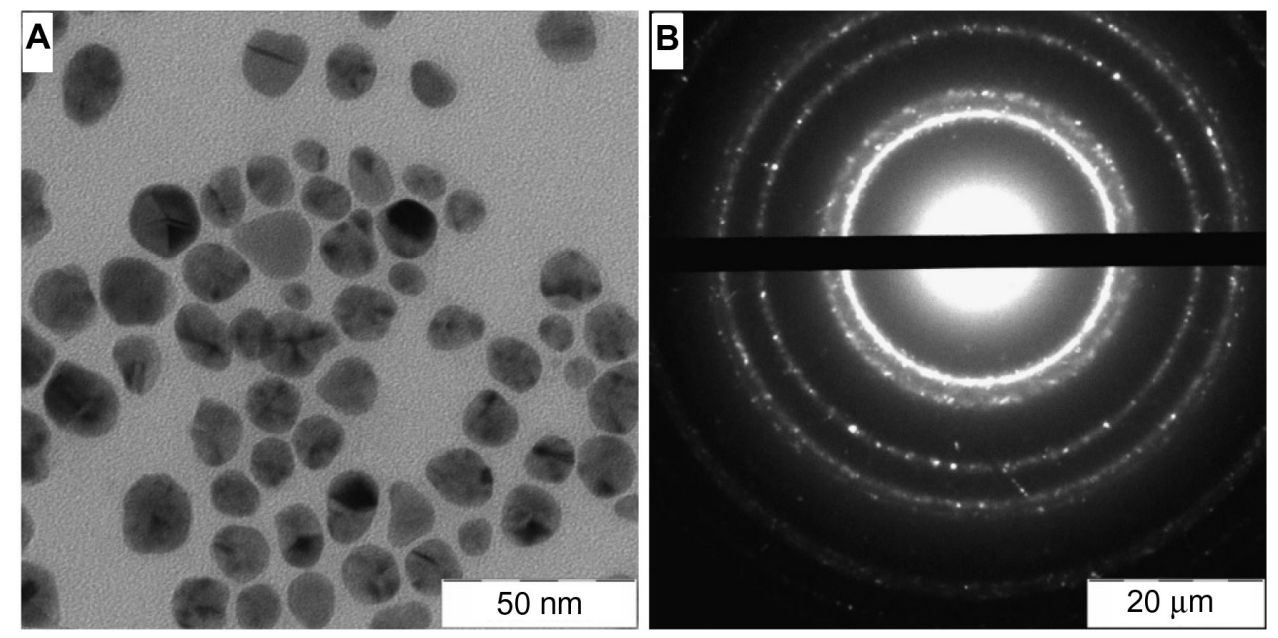

Figure I Electron micrograph (A) and diffraction pattern (B) of the Ag NPs in water solution used in this work. Abbreviation: Ag NPs, silver nanoparticles. 

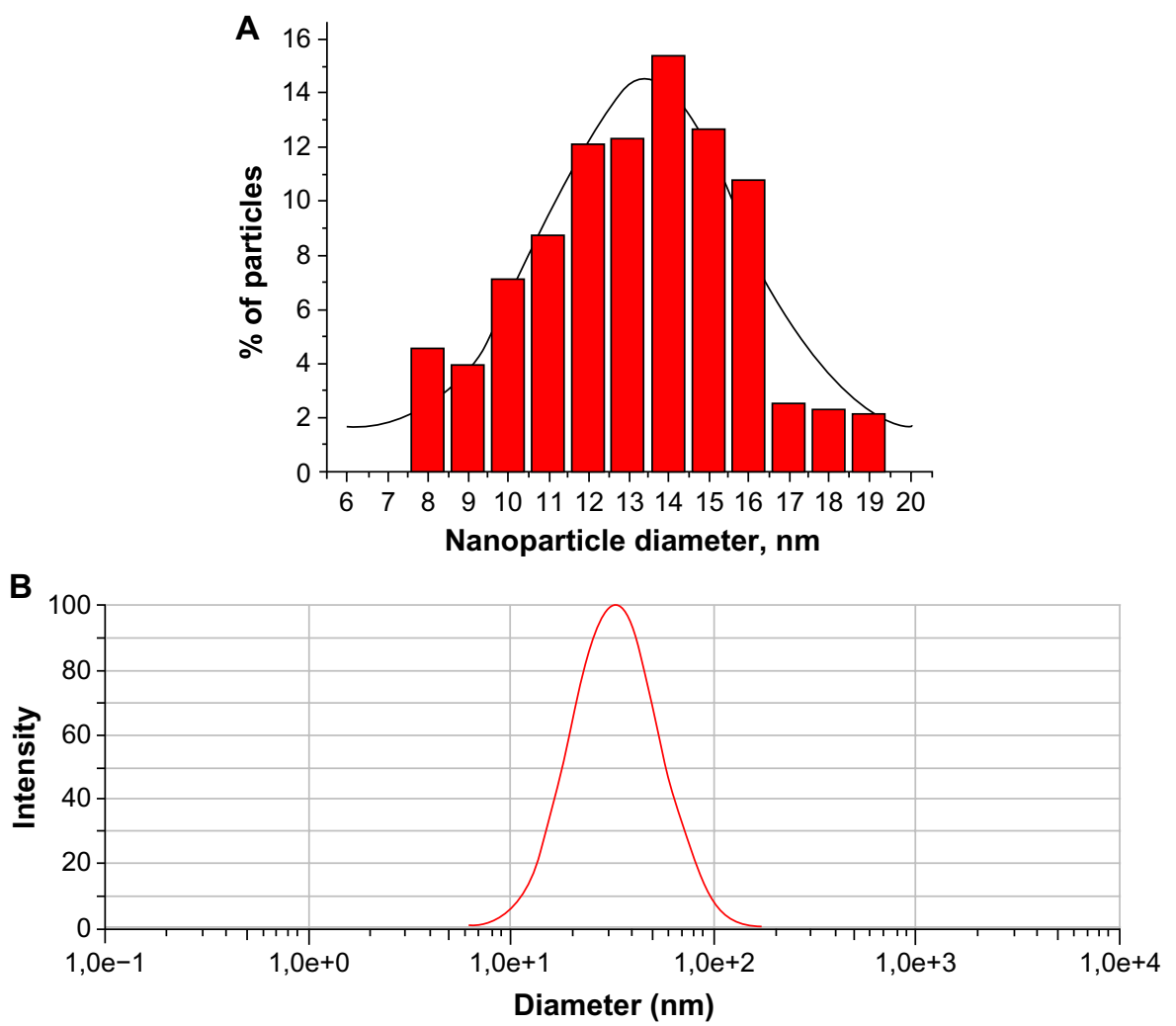

Figure 2 Size distribution of the nanoparticles in water solution obtained by transmission electron microscopy (A) and photon correlation spectroscopy (B).

with the corresponding results for AOT, are presented in Figure 3.

As suggested by us earlier in analysis of the antimicrobial effects of $\mathrm{Ag} \mathrm{NPs},{ }^{2}$ the NP concentration corresponding to the beginning of viability decrease could be regarded as the toxicity threshold (TT), which can be used as a characteristic of the toxicity of metal NPs. This criterion is applied also in this work for estimation of Ag NP toxic action toward cultured cells.

For HeLa cells (Figure 3A and B) viability decreased from $2.0 \mu \mathrm{g} / \mathrm{mL} \mathrm{Ag} \mathrm{NPs,} \mathrm{so} \mathrm{the} \mathrm{TT} \mathrm{values} \mathrm{were} \mathrm{equal} \mathrm{to}$ $2.0 \mu \mathrm{g} / \mathrm{mL}$ for both incubation times. Also, it was clear that both $\mathrm{AOT}$ and $\mathrm{Ag}^{+}$ions did not exert a noticeable influence on cell viability in the whole concentration range studied. Interestingly, here an increase in viability was observed at the lowest AOT and (at 24 hours' incubation) Ag NP concentrations, indicative probably of a stimulating action of these agents in the nontoxic range below the TT value.

For U937 cells (Figure 3C and D), a decrease in cell viability was also observed at both incubation times. A significant toxic effect was detected for $\mathrm{Ag} \mathrm{NPs}$ and $\mathrm{Ag}^{+}$ions, while the stabilizer (AOT) was less dangerous for cells in almost the whole concentration range. After 4 hours' incubation, an obvious decrease in cell viability compared to control was registered for $\mathrm{Ag}$ NPs and $\mathrm{Ag}^{+}$ions at $2.0 \mu \mathrm{g} / \mathrm{mL}$ and $1 \mu \mathrm{g} / \mathrm{mL}$, respectively. That is, the TT value for the NPs was twice as large as that for silver ions; ie, silver ions were found to be more toxic than the NPs. From $2.0 \mu \mathrm{g} / \mathrm{mL}$ up to $8.0 \mu \mathrm{g} / \mathrm{mL}$, both the Ag NPs and $\mathrm{Ag}^{+}$ions demonstrated an almost equal degree of toxicity. After 24 hours' incubation, for both agents a toxic effect was revealed from the smallest concentration studied $(0.5 \mu \mathrm{g} / \mathrm{mL})$, ie, the TT value was less than that found after 4 hours' incubation, and equal for NPs and silver ions. The toxic effect of AOT here was more pronounced, though obviously less than that of silver for all the concentrations, except for $8.0 \mu \mathrm{g} / \mathrm{mL}$.

It is worth noting that at both incubation times, cell viability at $8.0 \mu \mathrm{g} / \mathrm{mL} \mathrm{Ag} \mathrm{NPs} \mathrm{was} \mathrm{somewhat} \mathrm{higher} \mathrm{than}$ that at $4.0 \mu \mathrm{g} / \mathrm{mL}$. To our view, this may be connected with the NP aggregation and sedimentation in the cell medium leading to the decrease in concentration of biologically active particles.

As follows from the comparison of the data obtained for the two cell lines, HeLa cells appeared to be more resistant to the toxic action of $\mathrm{Ag}^{+}$ions than $\mathrm{U} 937$ cells. The reason lies probably in the different nature of the cells: for the adhesive cells (HeLa), part of their surface (adherent to the well surface) is less available for silver ions, while for suspension 

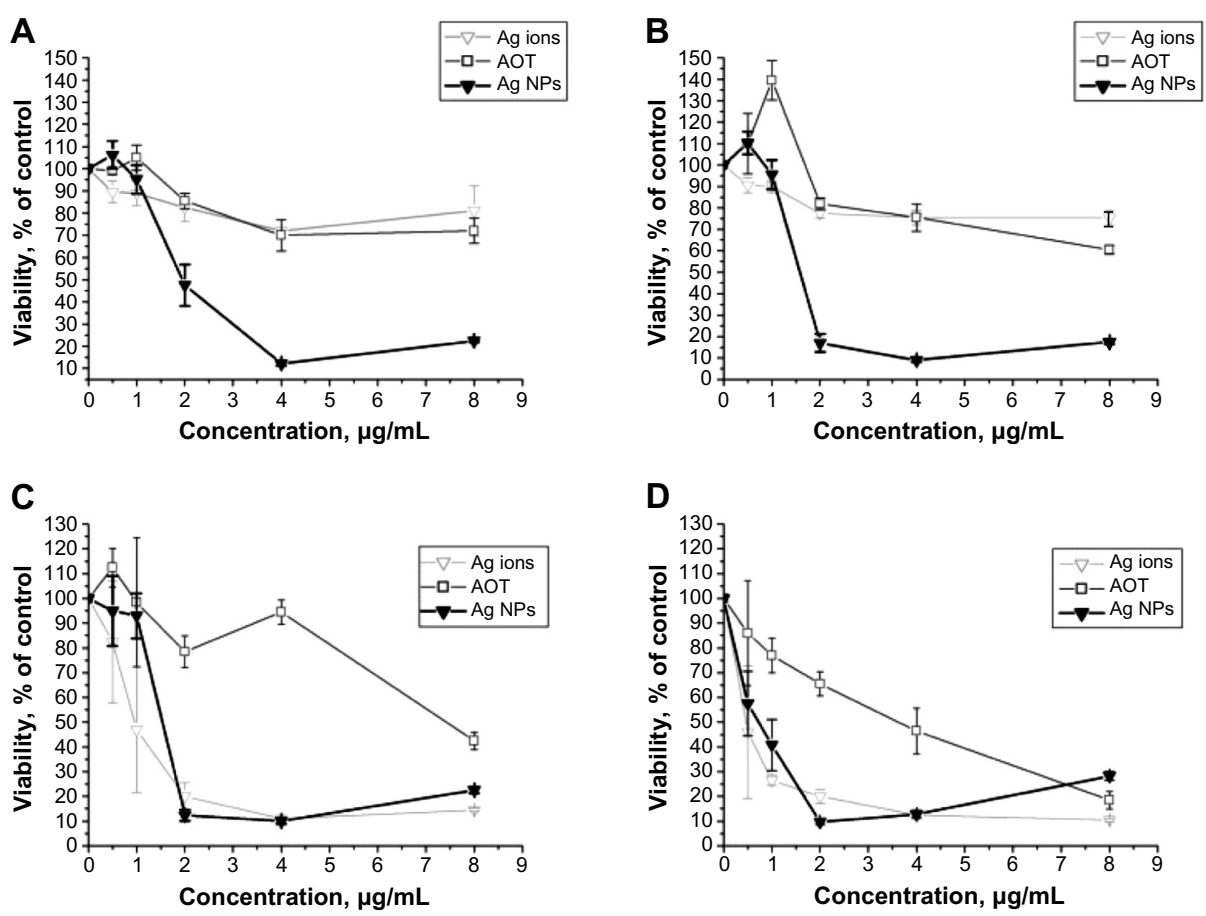

Figure 3 Viability of HeLa cells after 4 (A) and 24 hours' (B) incubation and U937 cells after 4 (C) and 24 hours' (D) incubation with Ag NPs, AOT and Ag ions at their various concentrations and incubation times (MTT assay).

Notes: Concentrations $(\mu \mathrm{g} / \mathrm{mL})$ are given for Ag NPs and $\mathrm{Ag}^{+}$ions. Results for AOT correspond to the relevant dilutions of the $2 \mathrm{mM}$ AOT water solution. Viability values were calculated as a percentage of cell viability in control (where deionized water was used as substitute of NP solution).

Abbreviations: Ag NPs, silver nanoparticles; AOT, aerosol-OT; MTT, 3-(4,5-dimethylthiazol-2-yl)-2,5-diphenyltetrazolium bromide.

cells (U937), their whole surface is readily available. Also, the difference in cell size may play a role: since U937 are smaller, for an equal cell number in unit volume of suspension, the total surface area (ie, surface of contact) of U937 is larger than that of HeLa, and hence the effect of $\mathrm{Ag}^{+}$ions may be more pronounced.

\section{Detection of early and late apoptotic and necrotic events}

In this study, differentiation between early and late apoptosis was performed. FITC-labeled annexin was used to determine cells at early apoptosis because of its capability to bind with phosphatidyl serine on the surface of apoptotic cells (in the presence of $\mathrm{Ca}^{2+}$ ions). Additional cell staining with PI allows for distinguishing between late apoptotic and necrotic cells during analysis. ${ }^{43}$

Therefore, it was possible to distinguish cells at various apoptosis stages from those in a necrotic state. Results were obtained as events registered in the FL1 (FITC) and FL2 (PI) channels of the cytofluorometer. Percentages of apoptotic and necrotic events were calculated after making FL1/FL2 dot-plot diagrams (data not shown). The data obtained from these diagrams were used to represent the relation between various events for each Ag NP concentration (Figure 4).
For HeLa cells, after 4 hours' incubation (Figure 4A) the percentage of living cells was lower compared to control at all Ag NP concentrations studied; their contribution decreased in the range $0-2.0 \mu \mathrm{g} / \mathrm{mL}$ (except for $0.5 \mu \mathrm{g} / \mathrm{mL}$ ) and then increased for 4.0 and $8.0 \mu \mathrm{g} / \mathrm{mL}$. At $2.0 \mu \mathrm{g} / \mathrm{mL}$, a noticeable increase in the percent of necrotic cells was observed, which correlated with the significant decrease in cell viability at this NP concentration (Figure 3A). At the two higher NP concentrations, the contribution of these dead cells was lower, while the percentage of apoptotic cells was higher (at $4 \mu \mathrm{g} / \mathrm{mL}$ ) or almost the same as that at $2 \mu \mathrm{g} / \mathrm{mL}$.

After 24 hours' incubation (Figure 4B) at $0.5-1.0 \mu \mathrm{g} / \mathrm{mL}$ of Ag NPs, the percentage of living cells remained practically equal to that found in the control. At $2.0 \mu \mathrm{g} / \mathrm{mL}$, an obvious decrease of living cell contribution and increase of that for cells in apoptotic and necrotic states was registered. Both results were in accordance with the corresponding data on viability given by the MTT test (Figure 3B). Again, at 4.0 and $8.0 \mu \mathrm{g} / \mathrm{mL}$, the contribution of dead cells was somewhat lower and that of early apoptotic cells higher than at $2.0 \mu \mathrm{g} / \mathrm{mL}$.

For U937 cells, after 4 hours' incubation (Figure 4C) the percentage of living cells tended to decrease monotonously with increase in Ag NP concentration. At the same time, the 

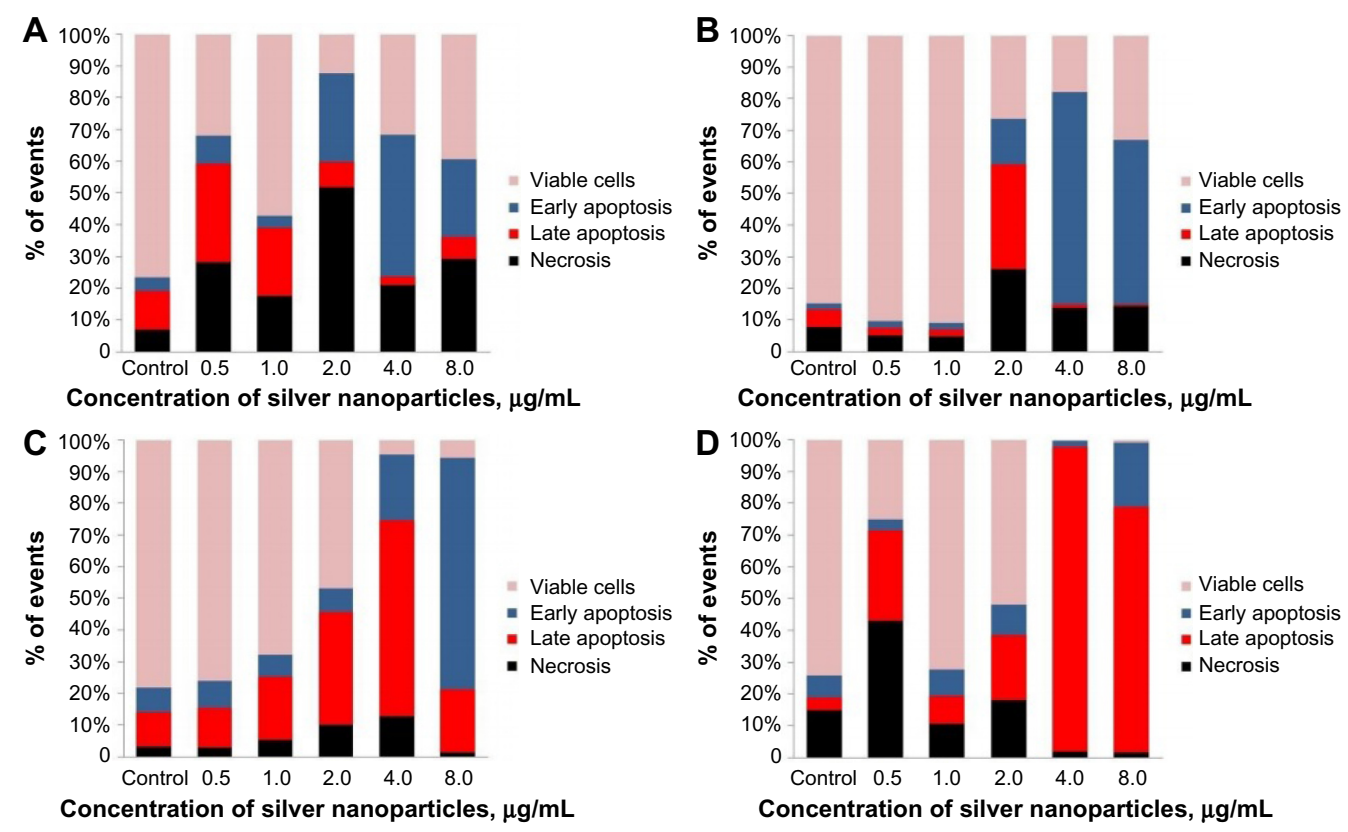

Figure 4 Apoptotic and necrotic events in HeLa after 4 (A) and 24 hours' (B) incubation and U937 cells after 4 (C) and 24 hours' (D) incubation with silver nanoparticles. Notes: Data obtained from flow cytofluorometry (FITC annexin and PI staining). Cells are shown as events detected by cytofluorometry and expressed in percentages (total amount of cells $=100 \%$ of events).

Abbreviations: FITC, fluorescein isothiocyanate; PI, propidium iodide.

percentage of apoptotic cells increased. From $1.0 \mu \mathrm{g} / \mathrm{mL}$ to $4.0 \mu \mathrm{g} / \mathrm{mL}$, cells at late apoptosis dominated over those at early apoptosis. Contrary to that, at $8.0 \mu \mathrm{g} / \mathrm{mL}$ cells were generally early apoptotic. The contribution of necrotic cells was low at all NP concentrations.

After 24 hours' incubation (Figure 4D), the level of necrotic cells incubated with $0.5-1.0 \mu \mathrm{g} / \mathrm{mL}$ of Ag NPs increased in comparison with cells after 4 hours' incubation. At $0.5 \mu \mathrm{g} / \mathrm{mL}$, a low percentage of living cells and a high percentage of necrotic cells was observed; this result was unexpected, taking into account the relatively high viability given for this NP concentration by the MTT assay (Figure 3D). At 4.0 and $8.0 \mu \mathrm{g} / \mathrm{mL}$ NP concentrations, the vast majority of cells were in a late-apoptosis state: no living, but almost no necrotic cells were found. This may have been associated with the aggregation of NPs and the corresponding decrease of the concentration of biologically active NPs in solution, in accordance with the increase of cell viability at $8.0 \mu \mathrm{g} / \mathrm{mL}$ of Ag NPs. Also, this may have resulted from cell proliferation during 24 hours' incubation with $8.0 \mu \mathrm{g} / \mathrm{mL}$ of Ag NPs.

To check our supposition of the aggregation of NPs as a possible reason for the enhanced viability of cells at higher concentrations of Ag NPs, we tried first to measure particle sizes by PCS in cell-culture media upon incubation with NPs. However, it turned out that this task could not be realized, because this technique does not reveal the nature of particles, and hence it was not possible to distinguish aggregates of $\mathrm{Ag}$ NPs from those formed by various cell-culture components, including combinations with NPs. Therefore, we used the nearest model available and measured particle sizes in PBS (without cells) incubated with 4.0 and $8.0 \mu \mathrm{g} / \mathrm{mL}$ of NPs for 1 and 2 hours at $37^{\circ} \mathrm{C}$. It was found that addition of Ag NPs led to the formation of bigger particles during the first hour of incubation, with no changes at longer times.

A typical result is shown in Figure 5. After 1 hours' incubation with $4 \mu \mathrm{g} / \mathrm{mL}$ Ag NPs (Figure 5A), the bimodal size distribution was found, with one peak of low intensity (at $60-100 \mathrm{~nm}$ ) and one peak of high intensity (at 670-720 nm); this distribution underwent practically no changes in the subsequent 1 or more hours of incubation (Figure 5B). A similar picture was observed with $8 \mu \mathrm{g} / \mathrm{mL}$ Ag NPs (Figure 5C and D), but here both peaks shifted to the bigger sizes, with the low-intensity peak at $150-170 \mathrm{~nm}$ and the high-intensity peak at $1,500-1,900 \mathrm{~nm}$. Since 1) mono- and bivalent cation concentrations in PBS were the same as in the cell-culture medium and 2) there were no other components in PBS capable of aggregation to the sizes observed except for Ag NPs, one can conclude that aggregation of Ag NPs (and the corresponding decrease in their toxicity) may take place at high Ag NP concentrations in cell culture. Formation of the Ag NP aggregates in cell-culture media with sizes in similar 

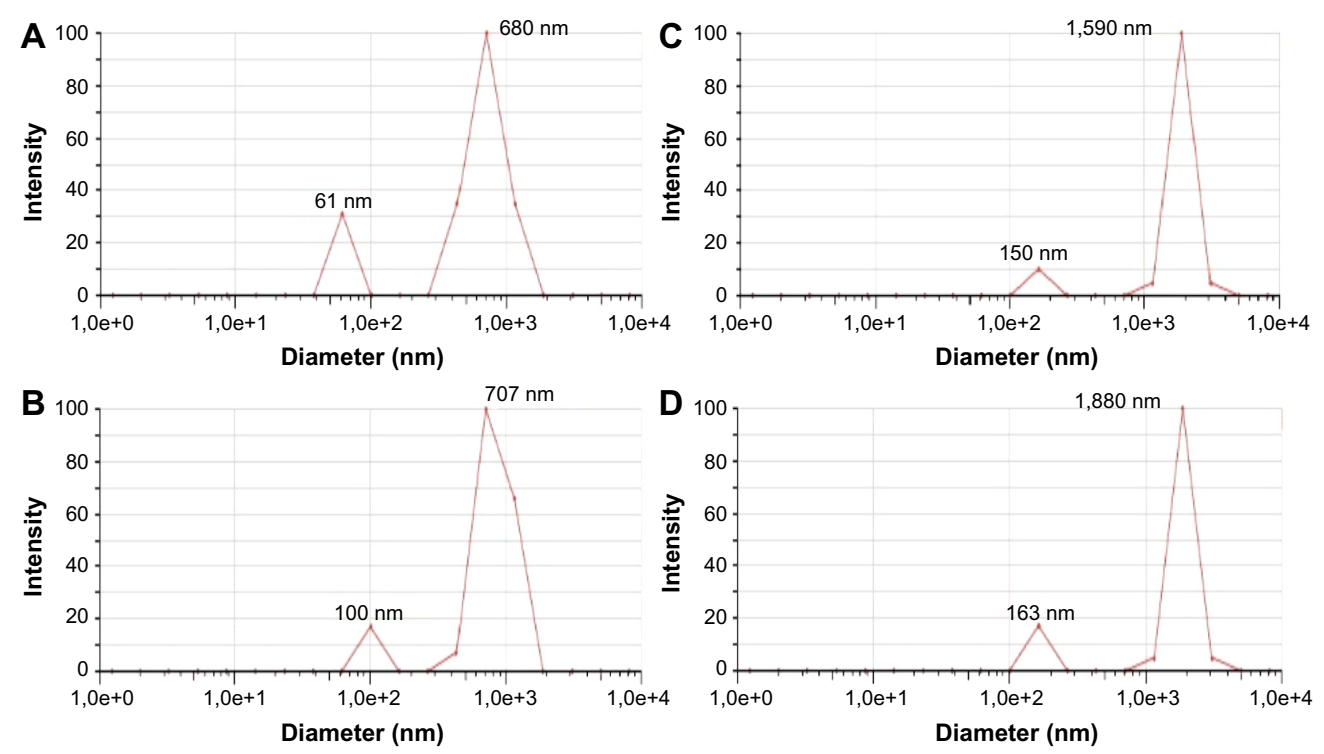

Figure 5 Particle-size distribution in phosphate-buffered saline after incubation with Ag NPs, measured by PCS.

Notes: Results are obtained with $4 \mu \mathrm{g} / \mathrm{mL}$ of $\mathrm{Ag} N P s$ after I (A) and 2 hours' incubation (B), and with $8 \mu \mathrm{g} / \mathrm{mL}$ of Ag NPs after I (C) and 2 hours' incubation (D). Sizes are given at the peak maxima. Pure PBS was used as control (no particles detected).

Abbreviations: Ag NPs, silver nanoparticles; PCS, photon correlation spectroscopy; PBS, phosphate-buffered saline.

range has also been noted by other authors. ${ }^{44,45}$ This is most likely provoked by NP association due to cation adsorption on their negative surface groups.

\section{Discussion}

As seen from the results presented, Ag NPs obtained by biochemical synthesis exhibited strong toxicity toward tumor cells in the concentration range studied. The effect was significant for both cell types, ie, for both adhesive and suspension cells. The TT lay at $0.5-2.0 \mu \mathrm{g} / \mathrm{mL}$. Comparison of NP toxicity with that of silver ions in equivalent concentrations showed that $\mathrm{Ag}^{+}$ions exerted no influence on the viability of HeLa cells, while for U937 they demonstrated strong toxicity equal to that of NPs. This probably reflects the different origin of the toxic action of Ag NPs: with HeLa, the cell viability is affected by the NPs themselves, but not by the metal ions released from their surface, while with U937 cells, the toxicity of NPs is mediated by the metal ions. Therefore, the toxic effect of Ag NPs may be realized through different mechanisms for the two cell types studied.

We found it useful to compare our results on cell viability with those in the literature, in studies of the toxicity of $\mathrm{Ag}$ NPs in vitro. Among this pool of data, we considered recent papers dealing with cancer cells where similar assays were applied. The results obtained for adhesive cells after 24 hours of incubation are presented in Table 1. As the main criterion for comparison, a TT value was used that could be easily found from the cell viability versus NP-concentration plots similar to those shown in Figure 3.

As seen in Table 1, the TT values obtained for the same cell line differed from each other, either by several times (with HeLa cells) ${ }^{44,46}$ or by orders. For example, with A431 (human skin carcinoma) cells, the TT varied from $1.51 \mu \mathrm{g} / \mathrm{mL}^{22}$ to $>50 \mu \mathrm{g} / \mathrm{mL},{ }^{47}$ and with $\mathrm{A} 549$ (human lung carcinoma epithelial-like cells) from $0.5 \mu \mathrm{g} /$ $\mathrm{mL}^{48}$ to $>50 \mu \mathrm{g} / \mathrm{mL} .{ }^{47}$ Such a discrepancy is unlikely to have resulted from different particle sizes, since it is clear that here the difference in particle sizes did not correlate with their toxicity: the TT values coincided for 50 and $100 \mathrm{~nm}$ $\mathrm{NPs}^{44}$ or differed significantly for particles of similar size range. ${ }^{21,22,46}$ It is also worth noting that the data considered do not support the widespread opinion about the higher biological activity of small particles compared to that of bigger ones. For example, the $2-5 \mathrm{~nm}$ NPs give a TT value of $60 \mu \mathrm{g} / \mathrm{mL},{ }^{46}$ while with the same cells, for $10-100 \mathrm{~nm}$ NPs this value is $10-20 \mu \mathrm{g} / \mathrm{mL} .{ }^{44}$ Also, for the other cells, smaller particles appear to be less toxic than bigger ones. ${ }^{47,48}$

Comparison with the TT value obtained by us for the adhesive cells after 24 hours' incubation $(2 \mu \mathrm{g} / \mathrm{mL})$ shows that it was significantly smaller than those obtained for the same cells by other authors. ${ }^{44,46}$ However, our result lies close to that found by Arora et a ${ }^{22}(1.56 \mu \mathrm{g} / \mathrm{mL})$ with A431 cells and Nowrouzi et a ${ }^{49}$ with HepG2 cells $(2.0 \mu \mathrm{g} / \mathrm{mL})$ for particles of similar size, and was only slightly higher than those obtained for some other cell types with smaller or 
Table I Cytotoxicity of Ag NPs: cell viability after 24 hours of incubation with NPs

\begin{tabular}{|c|c|c|c|c|c|}
\hline Ag NP preparation technique & Particle sizes, $\mathrm{nm}$ & Cell type & Cytotoxicity assay & Toxicity threshold, $\mu \mathrm{g} / \mathrm{mL}$ & Reference \\
\hline Unknown (commercial product) & $2-5$ & HeLa & Alamar blue assay & 60 & 46 \\
\hline \multirow[t]{3}{*}{ Unknown (commercial product) } & 10 & HeLa & CCK-8 (WST-based assay) & 10 & 44 \\
\hline & 50 & & & 20 & \\
\hline & 100 & & & 20 & \\
\hline \multirow[t]{2}{*}{ Unknown (patented preparation) } & $7-20$ & A43I & XTT assay & 1.56 & 22 \\
\hline & & HT-I080 & & 6.25 & \\
\hline \multirow[t]{2}{*}{ Chemical reduction } & $30-50$ & A43I & MTT assay & $>50$ & 47 \\
\hline & & A549 & & & \\
\hline \multirow[t]{2}{*}{ Unknown (commercial product) } & $>70$ (PVP-coated) & A549 & MTT assay & 0.5 (Ag NPs) & 48 \\
\hline & & & & $\mathrm{I}\left(\mathrm{Ag}^{+}\right)$ & \\
\hline \multirow[t]{4}{*}{ Unknown (commercial product) } & $<10$ & HepG2 & MTT assay & 0.5 (Ag NPs) & 21 \\
\hline & & & & $0.1\left(\mathrm{Ag}^{+}\right)$ & \\
\hline & & & Alamar blue assay & 0.7 (Ag NPs) & \\
\hline & & & & $0.7\left(\mathrm{Ag}^{+}\right)$ & \\
\hline Unknown (commercial product) & $5-10$ & HepG2 & MTT assay & 2.0 & 49 \\
\hline
\end{tabular}

Abbreviations: $\mathrm{Ag}^{+}$, silver ions; $\mathrm{Ag} \mathrm{NPs,} \mathrm{silver} \mathrm{nanoparticles;} \mathrm{WST,} \mathrm{water-soluble} \mathrm{tetrazolium;} \mathrm{XTT,} \mathrm{2,3-bis-(2-methoxy-4-nitro-5-sulfophenyl)-2H-tetrazolium-5-}$ carboxanilide; MTT, 3-(4,5-dimethylthiazol-2-yl)-2,5-diphenyltetrazolium bromide; PVP, polyvinylpyrrolidone.

bigger NPs. ${ }^{21,22,44,46}$ So it seems that at present, particle sizes in the initial NP solution do not play a role in viability, at least for the tumor cells considered here. The most probable reason for this may be particle aggregation in cell-culture medium, reported by various authors ${ }^{21,45}$ and observed also in this work.

It should be added that as follows both from our results and evidence present in the literature discussed, aggregated NPs remain biologically active toward various objects, including cultured cells. As demonstrated recently by Hackenberg et $\mathrm{al}^{25}$ on mesenchymal stem cells, the aggregation does not prevent silver particles from penetration into the cell interior, including the nucleus, with related cytotoxic and genotoxic effects.

Certain comments are needed about the contribution of silver ions to the toxic effects of NPs. It is obvious that water solutions of silver NPs can contain a certain amount of silver ions, either because of the incomplete reduction in the process of NP synthesis or produced by sonication of the aggregated particles aimed at obtaining the desired size distribution. Since $\mathrm{Ag}^{+}$ions are known to have strong biological activity, it is important to know their concentration and to minimize it or eliminate these ions if possible. Experimental evidence and exhaustive discussion of this point was given in the recent publication by Beer et al, ${ }^{20}$ where the toxicity of $\mathrm{Ag}$ NPs and $\mathrm{Ag}^{+}$ions was investigated on A549 cell culture. In particular, it was shown by MTT assay that 1) cell viability may be decreased after incubation with supernatant containing silver ions in comparison with a control $\left(\mathrm{H}_{2} \mathrm{O}\right)$, and 2$)$ cell viability depends on the content of $\mathrm{Ag}^{+}$ions present in the $\mathrm{Ag}$ NP preparation: the bigger the ions content, the smaller the percentage of viable cells.

As for our experiments, there was no need to measure the residual $\mathrm{Ag}^{+}$ion concentration, since there were no reasons to suggest the existence of residual silver ions in the Ag NP solution. First, with the biochemical synthesis method used by us, the highly effective reducing agent (Qr) provided practically $100 \%$ reduction and thus a $100 \%$ yield of NPs (see the "Silver nanoparticle synthesis and characterization" section). This peculiarity of our method is described in detail in our papers and recent book. 2,36,37 Second, we did not use sonication or any other method of artificial decrease of particle sizes. Therefore, there was no danger of $\mathrm{Ag}^{+}$ion release from the NP surface in the process of such pretreatment.

\section{Conclusion}

A water solution of Ag NPs obtained by an original method of biochemical synthesis was applied here for studies of Ag NP cytotoxicity on two types of tumor cells: adhesive (HeLa) and suspension (U937). Cytotoxicity was estimated as change in cell viability by MTT assay, as well as changes in their state (apoptosis and necrosis) by flow cytofluorometry. Minimal Ag NP concentration corresponding to the obvious decrease in cell viability (TT) after 4 hours' incubation was $2.0 \mu \mathrm{g} / \mathrm{mL}$ for both HeLa and U937 cells. After 24 hours' incubation the TT value for HeLa remained the same, while for U937 it became smaller $-0.5 \mu \mathrm{g} / \mathrm{mL}$. Control incubation with the stabilizer (AOT) at its concentration in the NP solution showed that AOT is less toxic than Ag NPs for both cell lines. Comparison with the effect of silver ions in concentrations equivalent to the silver 
concentrations introduced with $\mathrm{Ag}$ NPs revealed that $\mathrm{Ag}^{+}$ ions exerted no toxic effect on HeLa cells and demonstrated a toxicity practically equal to that of Ag NPs on U937 cells. This difference between the cell lines presumably resulted from the difference in cell-surface area available for silver ions.

Studies on the relationship among viable, apoptotic, and necrotic cells at each incubation time showed that after 4 hours' treatment, cell death mediated by apoptosis and necrosis increased in a dose-dependent manner. After 24 hours' treatment, a content of early and late apoptotic and necrotic cells changed: living cells turned early apoptotic (HeLa) or late apoptotic/necrotic (U937). We conclude that HeLa cells were more resistant to apoptosis-mediated death in comparison with U937, but cell viability was strongly decreased in both cell lines.

In summary, our results indicate the significant toxicity of Ag NPs obtained by biochemical synthesis toward the HeLa and U937 tumor cells. It follows that these NPs may prove to be a possible candidate for creation of corresponding antitumor drugs.

\section{Acknowledgment}

The authors would like to acknowledge the assistance provided by SS Abramchuk (Faculty of Chemistry, Moscow State University) for the particle characterization by TEM.

\section{Disclosure}

The authors report no conflicts of interest in this work.

\section{References}

1. Egorova EM. Biological effects of silver nanoparticles. In: Welles AE, editor. Silver Nanoparticles: Properties, Characterization and Applications. New York: Nova Science; 2010:221-258.

2. Egorova EM, Kubatiev AA, Shvets VI. Biological Effects of Metal Nanoparticles. 1st ed. Moscow: Nauka; 2014.

3. Lara HH, Garza-Treviño EN, Ixtepan-Turrent L, Singh DK. Silver nanoparticles as broad-spectrum bactericidal and virucidal compounds. J Nanobiotechnology. 2011;9:30.

4. Nadtochenko VA, Radtsig MA, Khmel IA. Antimicrobial effect of metallic and semiconductor nanoparticles. Nanotechnol Russ. 2010;5(5-6):277-289.

5. Rai M, Yadav A, Gade A. Silver nanoparticles as a new generation of antimicrobials. Biotechnol Adv. 2009;27(1):76-83.

6. Marambio-Jones C, Hoek EM. A review of the antibacterial effects of silver nanomaterials and potential implications for human health and the environment. J Nanopart Res. 2010;12(5):1531-1551.

7. Monteiro DR, Gorup LF, Takamiya AS, Ruvollo-Filho AC, de Camargo ER, Barbosa DB. The growing importance of materials that prevent microbial adhesion: antimicrobial effect of medical devices containing silver. Int J Antimicrob Agents. 2009;34(2):103-110.

8. Rejeski D. Nanotechnology and Consumer Products: CPSC Hearing. Washington: Project on Emerging Nanotechnologies; 2009. Available from: http://www.nanotechproject.org/publications/archive/ nanotechnology_consumer_products. Accessed November 7, 2014.
9. Ahamed M, Alsalhi MS, Siddiqui MK. Silver nanoparticle applications and human health. Clin Chim Acta. 2010;411(23-24):1841-1848.

10. Fabrega J, Luoma SN, Tyler CR, Galloway TS, Lead JR. Silver nanoparticles: behaviour and effects in the aquatic environment. Environ Int. 2011;37(2):517-531.

11. Neal AL. What can be inferred from bacterium-nanoparticle interactions about the potential consequences of environmental exposure to nanoparticles? Ecotoxicology. 2008;17(5):362-371.

12. Arora S, Rajwade JM, Paknikar KM. Nanotoxicology and in vitro studies: the need of the hour. Toxicol Appl Pharmacol. 2012;258(2): 151-165.

13. Oberdörster G, Oberdörster E, Oberdörster J. Nanotoxicology: an emerging discipline evolving from studies of ultrafine particles. Environ Health Perspect. 2005;113(7):823-839.

14. Stratmeyer ME, Goering PL, Hitchins VM, Umbreit TH. What we know and don't know about the bioeffects of nanoparticles: developing experimental approaches for safety assessment. Biomed Microdevices. 2010;12(4):569-573.

15. Dykman LA, Bogatyrev VA, Shchyogolev SY, Khlebtsov PG. [Gold nanoparticles: synthesis, properties, biomedical applications]. 1st ed. Moscow: Nauka; 2008. Russian.

16. Lopanov AN. [Silver]. 1st ed. St Petersburg: Agat; 2005. Russian.

17. Lystzov VN, Murzin NV. Safety Concerns of Nanotechnologies. Moscow: Moscow Engineering Physics Institute; 2007.

18. Mossman BT, Borm PJ, Castranova V, Costa DL, Donaldson K, Kleeberger SR. Mechanisms of action of inhaled fibers, particles and nanoparticles in lung and cardiovascular diseases. Part Fibre Toxicol. 2007;4:4.

19. Soloviev M. Nanobiotechnology today: focus on nanoparticles. J Nanobiotechnology. 2007;5:11.

20. Beer C, Foldbjerg R, Hayashi Y, Sutherland DS, Autrup H. Toxicity of silver nanoparticles - nanoparticle or silver ion? Toxicol Lett. 2012;208(3):286-292.

21. Kim S, Choi JE, Choi J, et al. Oxidative stress-dependent toxicity of silver nanoparticles in human hepatoma cells. Toxicol In Vitro. 2009;23(6):1076-1084.

22. Arora S, Jain J, Rajwade JM, Paknikar KM. Cellular responses induced by silver nanoparticles: in vitro studies. Toxicol Lett. 2008;179(2): 93-100.

23. Sur I, Cam D, Kahraman M, Baysal A, Culha M. Interaction of multifunctional silver nanoparticles with living cells. Nanotechnology. 2010;21(17):175104.

24. Sosenkova LS, Egorova EM. Small-sized silver nanoparticles for studies of biological effects. Russ J Phys Chem A. 2011;85(2):264-273.

25. Hackenberg S, Scherzed A, Kessler M, et al. Silver nanoparticles: evaluation of DNA damage, toxicity and functional impairment in human mesenchymal stem cells. Toxicol Lett. 2011;201(1):27-33.

26. Kawata K, Osawa M, Okabe S. In vitro toxicity of silver nanoparticles at noncytotoxic doses to HepG2 human hepatoma cells. Environ Sci Technol. 2009;43(15):6046-6051.

27. Lu W, Senapati D, Wang S, et al. Effect of surface coating on the toxicity of silver nanomaterials on human skin keratinocytes. Chem Phys Lett. 2010;487(1-3):92-96.

28. Kudryavtzev B, Figovsky O, Revina A, Egorova E, Buslov F, Beilin D. The use of nanotechnology in production of bioactive paints and coatings. J Sc Isr Technol Adv. 2003;5(1-2):209-215.

29. Shirokova LN, Alexandrova VA, Egorova EM, Vihoreva GA. [Macromolecular systems and bactericidal films based on chitin derivatives and silver nanoparticles]. Prikl Biokhim Mikrobiol. 2009;45(4):422-426. Russian.

30. Egorova EM, Beilina SI, Matveeva NB, Sosenkova LS. Chemotaxis-based assay for the biological action of silver nanoparticles. In: Williams TC, editor. Chemotaxis: Types, Clinical Significance and Mathematical Models. New York, Nova Science; 2011:157-187.

31. Matveeva NB, Egorova EM, Beilina SI, Lednev VV. Chemotactic assay for biological effects of silver nanoparticles. Biophysics. 2006;51(5):758-763. 
32. Egorova EM. Interaction of silver nanoparticles with biological objects: antimicrobial properties and toxicity for the other living organisms. J Phys Conf Ser. 2011;291(1):012050.

33. Maitra A. Determination of size parameters of water-aerosol OT - oil reverse micelles from their nuclear magnetic resonance data. $J$ Phys Chem. 1984;88(21):5122-5125.

34. Pileni MP, editor. Structure and Reactivity in Reverse Micelles. Amsterdam: Elsevier; 1989.

35. Egorova EM, Revina AA. Synthesis of metallic nanoparticles in reverse micelles in the presence of quercetin. Colloids Surf A Physicochem Eng Asp. 2000;168(1):87-96.

36. Egorova EM, Revina AA. Mechanism of the interaction of quercetin with silver ions in reverse micelles. Russ J Phys Chem. 2003;77(9): 1513-1521.

37. Egorova EM, Revina AA, Rumyantsev BV, Smirnov OK, Toidze ZG. Shishkov DI. Stable silver nanoparticles in aqueous dispersions obtained from micellar solutions. Russ J Appl Chem . 2002;75(10):1585-1590.

38. International Organization for Standardization. Water quality Determination of surfactants - Part 1: Determination of anionic surfactants by measurement of the methylene blue index (MBAS). 1996. Available from: http://www.iso.org/iso/catalogue_detail. htm?csnumber=24784. Accessed January 20, 2015.

39. Wilcoxon JP, Williamson RL, Baughman R. Optical properties of gold colloids formed in inverse micelles. J Chem Phys. 1993;98(12): 9933-9950.

40. Egorova EM. Biochemical synthesis, optical properties and sizes of gold nanoparticles. In: Bartul Z, Trenor J, editors. Advances in Nanotechnology. Vol 11. New York: Nova Science; 2014:119-146.
41. Denizot F, Lang R. Rapid colorimetric assay for cell growth and survival. Modifications to the tetrazolium dye procedure giving improved sensitivity and reliability. J Immunol Methods. 1986;89(2):271-277.

42. Monsmann T. Rapid colorimetric assay for cellular growth and survival: application to proliferation and cytotoxicity assays. J Immunol Methods. 1983;65(1-2):55-63.

43. Vermes I, Haanen C, Steffens-Nakken H, Reutelingsperger C. A novel assay for apoptosis. Flow cytometric detection of phosphatidylserine expression on early apoptotic cells using fluorescein labelled annexin V. J Immunol Methods. 1995;184(1):39-51.

44. Kim TH, Kim M, Park HS, Shin US, Gong MS, Kim HW. Sizedependent cellular toxicity of silver nanoparticles. J Biomed Mater Res A. 2012;100(4):1033-1043.

45. Lankoff A, Sandberg WJ, Wegierek-Ciuk A, et al. The effect of agglomeration state of silver and titanium dioxide nanoparticles on cellular response of HepG2, A549 and THP-1 cells. Toxicol Lett. 2012;208(3): 197-213.

46. Miura N, Shinohara Y. Cytotoxic effect and apoptosis induction by silver nanoparticles in HeLa cells. Biochem Biophys Res Comm. 2009;390(3): 733-737.

47. Kaur J, Tikoo K. Evaluating cell specific cytotoxicity of differentially charged silver nanoparticles. Food Chem Toxicol. 2013;51:1-14.

48. Foldbjerg R, Dang DA, Autrup H. Cytotoxicity and genotoxicity of silver nanoparticles in the human lung cancer cell line, A549. Arch Toxicol. 2011;85(7):743-750.

49. Nowrouzi A, Meghrazi K, Golmohammadi T, et al. Cytotoxicity of subtoxic AgNP in human hepatoma cell line (HepG2) after long-term exposure. Iran Biomed J. 2010;14(1-2):23-32.
Nanotechnology, Science and Applications

\section{Publish your work in this journal}

Nanotechnology, Science and Applications is an international, peer-reviewed, open access journal that focuses on the science of nanotechnology in a wide range of industrial and academic applications. It is characterized by the rapid reporting across all sectors, including engineering, optics, bio-medicine, cosmetics, textiles, resource sustainability and science. Applied research into nano-materials,

\section{Dovepress}

particles, nano-structures and fabrication, diagnostics and analytics, drug delivery and toxicology constitute the primary direction of the journal. The manuscript management system is completely online and includes a very quick and fair peer-review system, which is all easy to use. Visit http://www.dovepress.com/ testimonials.php to read real quotes from published authors. 